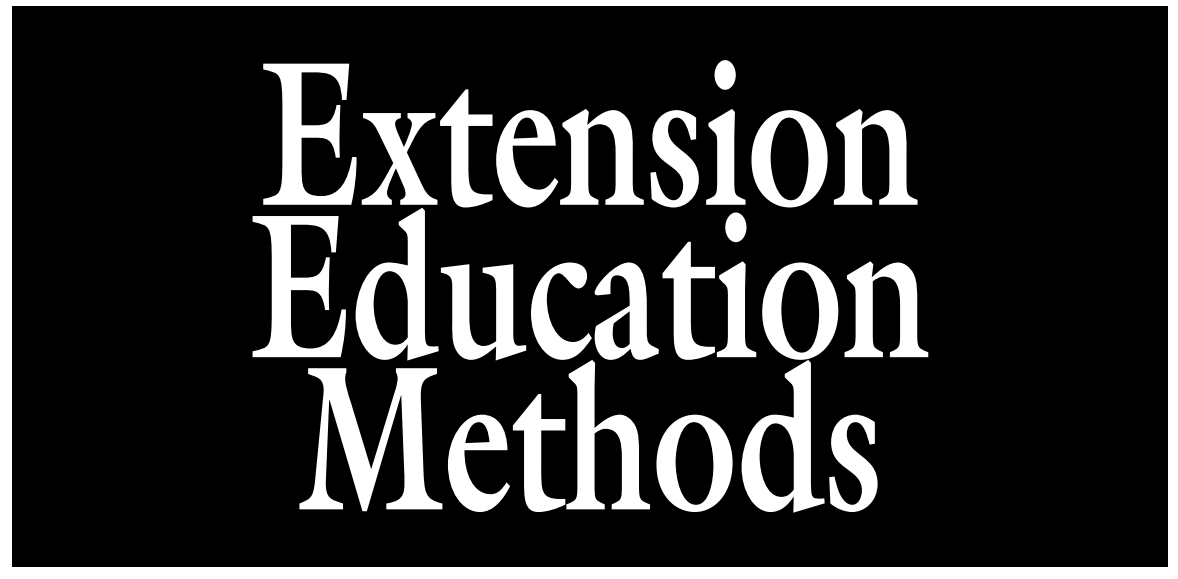

\title{
Learning Preferences of Next Generation Hispanic/Latino Specialty Crop Growers
}

\author{
Tara Baugher ${ }^{1,4}$, Montserrat Fonseca Estrada ${ }^{1}$, Kelly Lowery ${ }^{2}$, \\ and Héctor Núñez Contreras ${ }^{3}$
}

\begin{abstract}
AdDitionAl INDEX wORDs. extension education and outreach, adult learning, experiential learning

Summary. A bicultural team of Penn State Extension professionals assessed educational method and learning style preferences of Hispanic/Latino stakeholders who aspire to be next generation specialty crop growers and specialized horticultural managers. During 2014-16, team members conducted and evaluated bilingual programs in various formats, including in-depth workshops, model demonstration plots, on-farm trainings and tours, fact sheets and field guides, and videos. Postprogram surveys indicated formats that provided opportunities for active learning of research-based information applicable to participant operations were most successful. Purposive surveys and interviews identified further ways to adapt extension outreach and education for next generation growers. The top-rated methods of learning for Hispanic/Latino growers were on-farm demonstrations and study circles, tours of other growers' farms, self-paced on-line courses and videos, and interactive workshops. Factors Hispanic/Latino grower survey respondents felt limited them from participating in educational activities or using extension resources were timing of program, cost, and location. Survey participants suggested extension might improve education and engagement with Hispanic/ Latino growers by increasing the use of social media in Spanish, holding educational programs specifically for Latino farmers to increase networking opportunities, and holding educational events at the farms of Latino growers.
\end{abstract}

$\mathrm{T}$ he 2012 Census of Agriculture [U.S. Department of Agriculture (USDA), 2014] indicates that Hispanic/Latino farm owners represent a promising next generation of specialty crop growers. While principal operators of all farms decreased by $4 \%$ between 2007 and 2012, Hispanic principal operators increased by $21 \%$, and average age was younger (USDA, 2014). U.S. horticultural crop sales increased 18\% between 2009 and 2014, which represents a significant opportunity for a rising generation of aspiring Hispanic/ Latino growers (USDA, 2016).
There is a paucity of research on extension and outreach programming specific to the needs of Hispanic/ Latino specialty crop producers. However, studies with other groups of adult agricultural learners indicate trends that may also apply to this group of adult learners. Several studies have shown that active learning techniques are highly effective with adults who participate in agricultural extension programs. Strong et al. (2010) looked at the perceptions of extension educators who facilitated various teaching strategies for adult farmers and reported that hands-on learning was considered more effective than lectures and slideshow presentations. Irani et al. (2003) also evaluated adult learning through the perspective of educators and found that use of a variety of active learning strategies was associated with the motivation to learn. Surveys of university personnel and producers indicated extension educators could better align teaching styles with learning styles through hands-on demonstrations and participatory programs (Johnson et al., 2008). Participants suggested more programming on producers' farms with extension personnel facilitating educational networking.

Evaluations of teaching methods specific to the needs of young and women learners have revealed similar trends. Trede and Whitaker (2000) conducted surveys of beginning farmers and identified experiential learning and problem-solving activities that involve both physical and mental capacity as key to the promotion of critical thinking. Dollisso and Martin (1999) assessed learning preferences of members of a young farmer association and found practical, hands-on experiences were most preferred. A survey of women farmers found participationstyle workshops and on-farm demonstrations were preferred educational formats (Barbercheck et al., 2009). Women with less than 5 years of experience also expressed a preference for interactive learning opportunities that included peer teaching and networking.

Andragogy, the study of how adults learn, can provide a guiding framework for developing extension educational programming specific to adult learner needs and preferences (Irani et al., 2003; Ota et al., 2006; Strong et al., 2010). Fundamental principles of adult learning include active participation, relevance to life and work experiences, engagement through problem solving rather than subject content, and connection to communities of practice and purpose (Knowles et al., 2005). Ota et al. (2006) reviewed andragogy principles that have applications to $\mathrm{ex}^{-}$ tension education and proposed an increased focus on experiential techniques that connect to learner experiences. Suggestions included case study simulations, problem-solving activities, group discussion, and role play. Case studies and problem-solving 
activities enable adult learners to examine real-world situations, applying their own experiences with acquired knowledge, to determine pragmatic solutions. Discussions and role play engage participants in sharing experiences to connect with subject matter, and result in critical thinking and practice adoption.

The goals of this project were to 1) assess extension education methods for Hispanic/Latino stakeholders who aspire to be next generation specialty crop growers and specialized horticultural managers, and 2) evaluate learning style preferences of adult Hispanic/Latino horticulturists relative to extension and outreach programming. Adult learning principles provided the theoretical framework for this project that was led by a bicultural team of Penn State Extension educators and specialists.

\section{Materials and methods}

During 2014-16, team members conducted and evaluated various formats of extension programming in Spanish, including interactive workshops, model demonstration plots, on-farm trainings and tours, fact sheets and field guides, and videos. During the 2nd year of the project, we conducted surveys and interviews

\footnotetext{
This project was supported by a Pennsylvania Department of Agriculture Specialty Crop block grant titled "Sustainable Production and Market Innovations for Next Generation Young and Hispanic Specialty Crop Growers" (Project number ME44144963) and a National Institute of Food and Agriculture, U.S. Department of Agriculture grant titled "Supporting Pennsylvania New Farmers in the Start-up, Restrategizing and Establishing Years" (Award number 2015-70017-22852)

We acknowledge the valuable contributions of Tianna Dupont, Kerry Richards, Miguel Antonio Saviroff, Maria Gorgo Gourovitch, Winifred McGee, Marley Skinner, Lee Stivers, James Schupp, Alana Anderson, Kristi Kraft, Michael Basedow, and Tom Jarvinen (Penn State Extension); Corey and Vicky McCleaf, Bruce Hollabaugh, and Allison Crowell (grower collaborators); and Jorge Perez-Rico, Suzanne Benchoff (Pennsylvania Department of Education Migrant Program) and Arturo Diaz (Casa de la Cultura) who served as project advisors. We especially thank the Hispanic/Latino specialty crop growers who suggested we develop bilingual horticulture extension programming specific to their educational interests and also those producers who participated in
} surveys and interviews.

${ }^{1}$ Penn State Extension, 670 Old Harrisburg Road, Gettysburg, PA 17325

${ }^{2}$ Penn State Extension, 222 Special Services Building, University Park, PA 16802

${ }^{3}$ South Mill Mushrooms, 649 West South Street, Kennett Square, PA 19348 (formerly with Penn State Extension)

${ }^{4}$ Corresponding author. E-mail: tab36@psu.edu.

doi: 10.21273/HORTTECH03581-16 of Hispanic/Latino horticulturists who had participated in a variety of the educational formats offered in Spanish. All educational programs were designed to follow researchbased guidelines for building trust/ positive relationships and providing culturally responsive outreach to firstand second-generation Hispanic/ Latino communities (Farner et al., 2005; Hobbs, 2004; Olsen and Skogrand, 2009; Vega et al., 2016).

IN-DEPTH WORKSHOPS. A team of bilingual adult educators designed and implemented workshop lesson plans that incorporated role play, case study simulations, and various other interactive, problem-solving activities as suggested by Knowles et al. (2005) and Ota et al. (2006). Role play was used to help learners practice scenarios relevant to their farm interests. For instance, during a session on identifying potential markets for horticultural crops, learners role-played various strategies for interviewing restaurant and store managers. Short case studies (also referred to as critical incidents) facilitated critical thinking skills relative to crop production situations or problems. For example, a case study simulation following a group discussion on protecting pollinators engaged learners in identifying possible reasons for the discovery of dead and disoriented honeybees (Apis mellifera) in front of a hive. Other participatory activities included introductory discussions to engage attendees in defining the scope of a workshop, ice-breaker games that helped gauge prior experiences relative to a topic, and round table sessions facilitated by specialty crop grower mentors.

MODEL DEMONSTRATION PLOTS AND STUDY CIRCLES. On-farm, model vegetable demonstration plots served as "living classrooms" where Hispanic/ Latino learners practiced sustainable growing methods and compared production and economic performance of various cropping systems. The demonstration plots also served as sites for study circle networks that engaged a broader community of learners. The model plot and study circle curricula are described in detail at the Penn State Extension "Start Farming" website (Penn State Extension, 2016) under "Courses and Workshops."

ON-FARM TRAININGS AND TOURS. Learners who participated in this project had the opportunity to visit with other Hispanic/Latino farmers during on-farm tours and trainings. The tours provided a variety of experiential learning formats including hands-on demonstrations on fruit tree pruning and field walks to learn crop scouting skills.

Our team developed fact sheets, field scouting guides, and videos to supplement the hands-on, problemsolving learning modules. These were produced in both Spanish and English, and in both hard copy and electronic formats. The videos were used during in-depth workshops and also serve as two initial modules in online horticulture trainings for Hispanic learners.

Two educators on our team had formal training in adult learning, and they engaged the learners in postprogram evaluations to assess presentation techniques used during the face-to-face field and classroom trainings. All program participants contributed to the follow-up evaluations by completing a standardized questionnaire designed to provide feedback relative to four key adult learning principles: 1) opportunities for active participation, 2) depth of engagement, 3 ) relevance to life and work, and 4) development of problemsolving skills. During 30-min open discussions at the conclusion of each program, participants informally shared details on relevance of the specific program topics to their professional goals.

Purposive surveys and interviews were conducted to assess 1) methods of learning preferred by Hispanic/ Latino growers, 2) ways extension might increase and improve education and engagement with Hispanic/ Latino growers, and 3) factors that might limit Hispanic/Latino specialty crop growers from participating in extension educational activities and/or using extension resources. Written surveys that began with a consistent set of five multiple choice questions (followed by program-specific questions) were conducted following three workshops for Hispanic/Latino specialty crop growers. Sixty-one participants (out of a total of 70) voluntarily completed the surveys after being advised of the purpose of the study. Nine Hispanic/Latino learners who had attended a variety of extension offerings in Spanish were individually interviewed. The same five questions 
were asked, and participants were encouraged to provide reasons for the answers selected.

\section{Results and discussion}

YEAR 1: POSTPROGRAM DISCUSSIONS/EVALUATIONS TO ASSESS EDUCATION METHODS. Feedback on presentation techniques used during workshops, field demonstrations, study circles, and tours in the first year of the project indicated trends similar to those described for other adult agricultural learners. The most successful formats provided opportunities for active learning of researchbased information that was applicable to participant operations. This feedback helped us to develop the following general facilitation outline for future sessions for Hispanic/Latino learners: 1) begin with a social activity or icebreaker to engage participants in sharing problem-solving goals for the session and to determine how to make topics most relevant to their work and life experiences, 2) conduct a short, interactive exercise to gauge current knowledge and practices, 3) explore multiple ways of transforming lecture-style teaching practices into problem-based learning, using collaborative and activity-based approaches, 4) where possible, involve experienced growers as mentors, 5 ) include an opportunity for networking with the other grower learners (e.g., a meal is an essential part of study circles), and 6) conclude with a time for reflection during which participants share what they learned relative to their goals and experiences.

YEAR 2: SURVEYS AND INTERVIEWS TO ASSESS LEARNING PREFERENCES RELATIVE TO OUTREACH
AND EXTENSION PROgRAMming. Purposive surveys and interviews conducted during Year 2 of the project identified further ways to adapt extension outreach and education for bilingual learners.

DEMOgRAPHIC CHARACTERISTICS OF SURVEY PARTICIPANTS. Participants who completed questionnaires represented a range of years of experience in specialty crop production and years of experience with extension programs in Spanish (Table 1). Twentyseven percent had been involved in horticultural production for less than 5 years, $39 \%$ for 5 to 10 years, and $34 \%$ for over 10 years. Individual growers had multiple areas of specialty crop production experience, with the highest responses being tree fruit followed by vegetable production. Experience with extension programs in Spanish ranged from 36\% for 1 to 2 years, to $38 \%$ for 3 to 4 years, and $26 \%$ for over 4 years.

RATINGS OF METHODS OF LEARNING BASED ON EXPERIENCES AND PREFERENCES. Survey participants rated seven methods of learning on a 1 to 5 scale, with 1 being "poor" and 5 being "highly effective." Participants responded that they liked a variety of educational methods, with their top choices being on-farm demonstrations and study circles, tours of other growers' farms, self-paced online courses and videos, and interactive workshops (Fig. 1). Interviewed Hispanic/Latino growers provided additional insights into learning preferences, stating that during on-farm trainings and interactive workshops they have the opportunities to "see things the way they are, not just theory," "share experiences," and "compare field results and generate new ideas." They liked "handson" formats more than "principles or lectures." They also indicated why they liked a mix of educational formats. In the words of one grower, "during on-farm presentations you are able to ask; in the fact sheets and production guides there are things that a speaker doesn't have time to address; and during in-depth workshops there's a lot more information." Many of the preferences were similar to those cited in previous studies on educational perceptions for young (Trede and Whitaker, 2000 ) and women (Barbercheck et al., 2009) start-up farmers. For example, $80 \%$ of responses by beginning women farmers indicated a preference for on-farm demonstrations, and beginning young farmers preferred experiential, problem-solving learning activities. Several studies with beginning farmers have indicated a need for a variety of educational formats. For example, young farmers who participated in a survey conducted by Dollisso and Martin (1999) indicated they preferred to learn by a variety of methods compared with either self-study or group instruction.

RATINGS OF WAYS EXTENSION AND OTHER AG PROFESSIONALS MIGHT INCREASE/IMPROVE EDUCATION AND ENGAgEMENT WiTH Hispanic/ LATINO GROWERS. Survey participants rated nine stakeholder engagement options on a 1 to 5 scale, with 1 being "poor" and 5 being "highly effective." The recommendations for increasing and improving education and engagement with Hispanic/ Latino growers were not significantly

Table 1. Demographic characteristics of Hispanic/Latino specialty crop growers who completed a postprogram, written questionnaire following three interactive workshops conducted in Spanish. Sixty-one participants (out of a total of 70) voluntarily completed multiple choice questions designed to assess learning style preferences of adult Hispanic/Latino horticulturists relative to extension and outreach programming. Adult learning principles provided the theoretical framework for this project that was led by a bicultural team of Penn State Extension educators and specialists. ${ }^{\mathrm{z}}$

\begin{tabular}{|c|c|c|c|c|c|}
\hline \multicolumn{2}{|c|}{$\begin{array}{l}\text { Experience in specialty } \\
\text { crop production }\end{array}$} & \multicolumn{2}{|c|}{ Areas of production experience ${ }^{y}$} & \multicolumn{2}{|c|}{$\begin{array}{l}\text { Experience with extension } \\
\text { programs in Spanish }\end{array}$} \\
\hline Duration (yr) & Participants (\%) & Production area & Responses (\%) & Duration (yr) & Participants (\%) \\
\hline $1-2$ & 7 & Small fruit production & 13 & 2 & 21 \\
\hline $3-4$ & 13 & Tree fruit production & 55 & 3 & 23 \\
\hline $5-10$ & 39 & Food safety & 4 & 4 & 15 \\
\hline
\end{tabular}

IPM = integrated pest management.

${ }^{\mathrm{z}}$ Presented as a percentage of the total $(n=61)$.

${ }^{\mathrm{y}}$ Multiple answers accepted. 
different, but those with the highest ratings were use of social media in Spanish, holding some educational programs specifically for Latino farmers to increase networking opportunities, and holding educational events at the farms of Latino growers (Fig. 2). The three options in this cluster were followed closely by creating opportunities for Latino growers to network with extension personnel and ag service providers, inviting Latino growers to participate in educational programs as round-table participants and/or

\section{Median rating (1-5 scale) of method of learning}

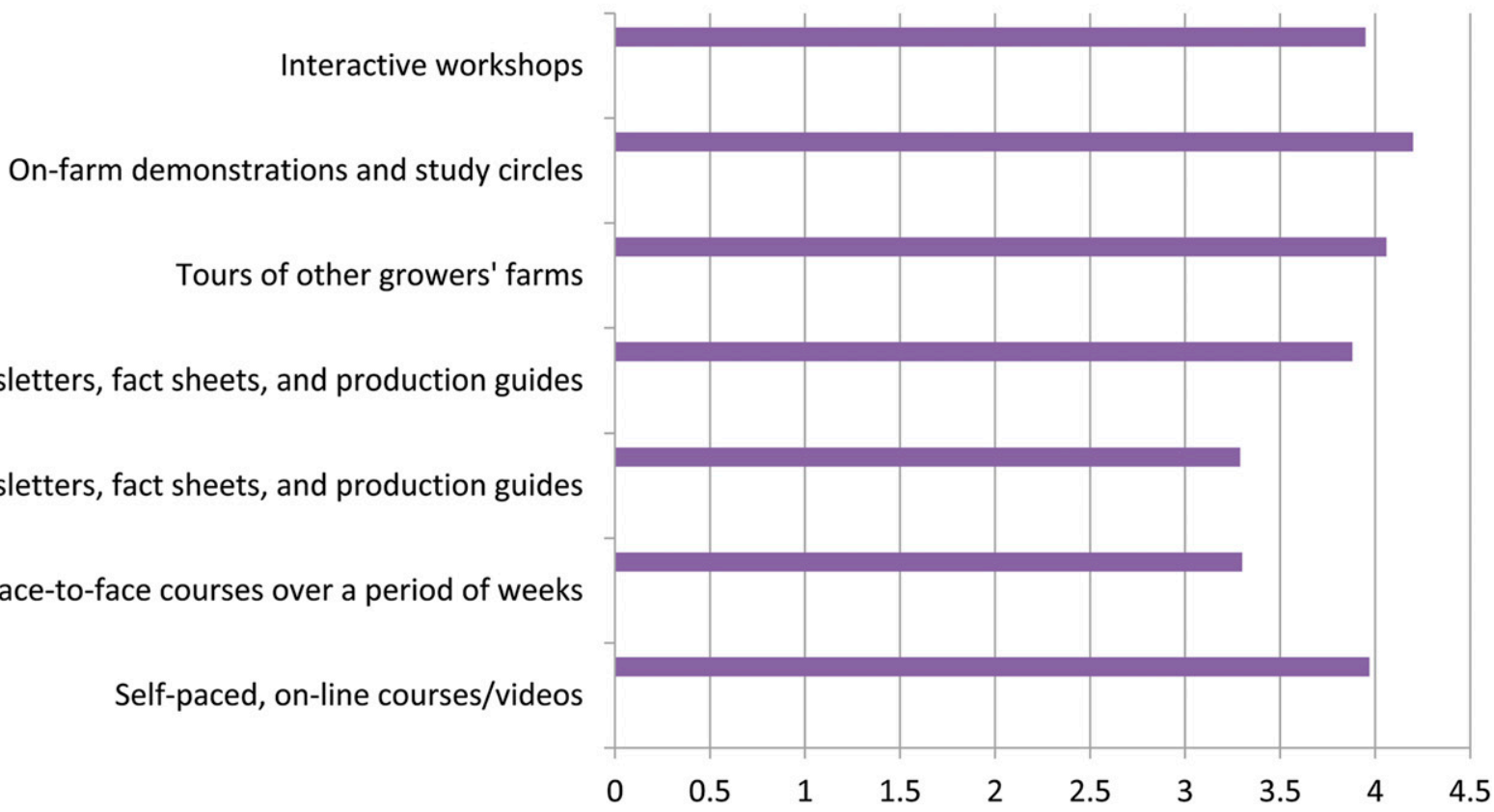

Fig. 1. Median ratings of methods of learning, based on experiences and preferences, of Hispanic/Latino specialty crop growers who completed a postprogram, written questionnaire following three interactive workshops conducted in Spanish. Survey participants rated seven methods of learning on a 1 to 5 scale, with $1=$ "poor" and $5=$ "highly effective" ( $\mathrm{n}=61$ ).

\section{Median rating (1-5 scale) of method of engagement}

Hold some educational programs specifically for Latino farmers to
increase networking opportunities

Create opportunities for Latino growers to network with Extension personnel and ag service providers

Increase use of social media, in Spanish, for outreach and education

Hold educational events at the farms of Latino growers

Provide more opportunities for "distance education" (on-line courses in Spanish)

Provide more opportunities for classroom education in Spanish (e.g., in cooperation with local community colleges or literacy programs)

Invite Latino growers to help plan events and serve on advisory committees

Invite Latino growers to participate in educational programs as round table participants and/or mentors

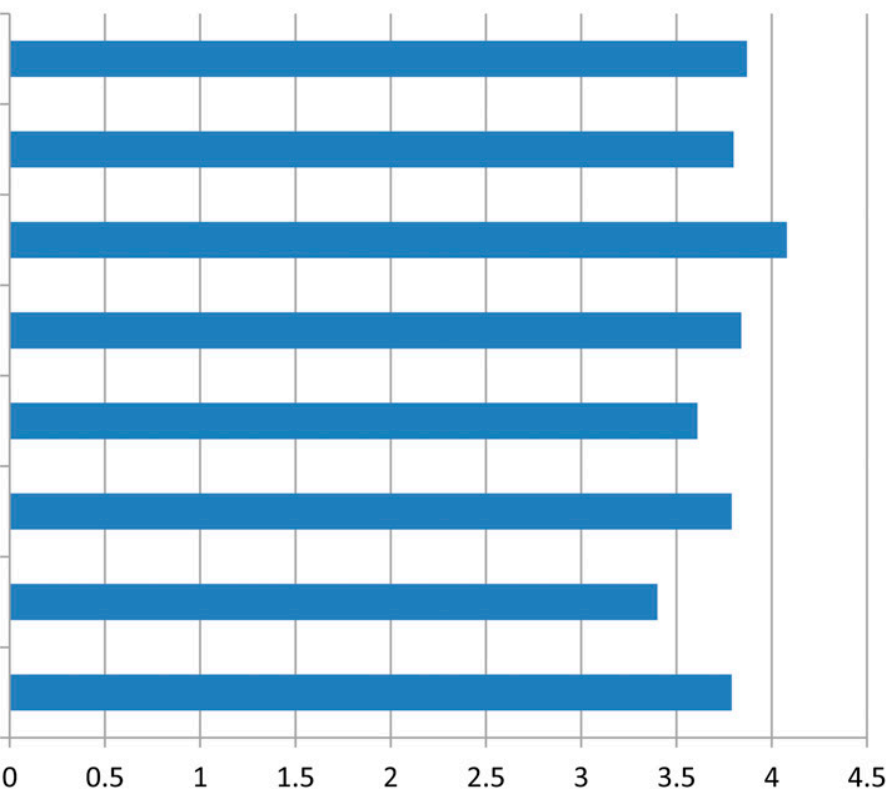

Fig. 2. Median ratings of ways extension and other ag professionals might increase/improve education and engagement with Hispanic/Latino growers. Survey participants rated nine stakeholder engagement options on a 1 to 5 scale, with $1=$ "poor" and 5 = "highly effective" $(n=61)$. 
mentors, and providing more opportunities for classroom education in Spanish in cooperation with local community colleges or literacy programs. Growers who were interviewed offered additional suggestions, including "offering credits or help with certifications," "improving communication on topics of interest to workshop participants," and "motivating growers to attend programs by helping them to see possible career benefits." Similar to studies conducted in rural Washington (Mullinix et al., 2006), Hispanic/Latino fruit and vegetable growers valued opportunities for career advancement and were most likely to seek out community-based programs.

FACTORS THAT LIMIT PARTICIPATION IN EXTENSION PROGRAMS AND UTILIZATION OF EXTENSION RESOURCES. Survey participants had the opportunity to select multiple limitations regarding extension program participation.
Hispanic/Latino growers indicated that timing of the program (e.g., avoiding busy seasons such as planting or harvest) was the greatest limitation [46\% of total responses (Fig. 3)]. Other major deterrents included cost, location, and length of program. Session or resource not in Spanish received slightly fewer responses, a total of $25 \%$. By comparison, negative past experiences, not being aware of sessions, and topics not relevant received $10 \%$ to $15 \%$ of total responses. Many of the growers who were interviewed replied that nothing would limit them from participating in extension programs or using extension resources. One grower explained more about the importance of program timing, suggesting that it was important to avoid scheduling programs during the busiest times of the growing season. Another grower explained that it is easier to learn technical information in Spanish but growers also like to attend programs in English so they can improve their language proficiency. These findings were similar to those reported by Hobbs (2004) in an article on extension outreach programs for first- and second-generation Hispanic/Latino audiences. Irregular work schedules indicated program timing was highly important, and Latino adults, even those fluent in English, appreciated the respect shown for their culture with Spanish or bilingual communication.

\section{Project limitations}

Building trusting extension relationships with minority stakeholders takes time and commitment. As a result the survey sample size was suboptimal for making fixed conclusions on learning style and educational method preferences. Hispanic/Latino communities are diverse, and it is important that extension educators gauge participant learning preferences on an ongoing basis and be ready to adapt as needed. The surveys conducted after

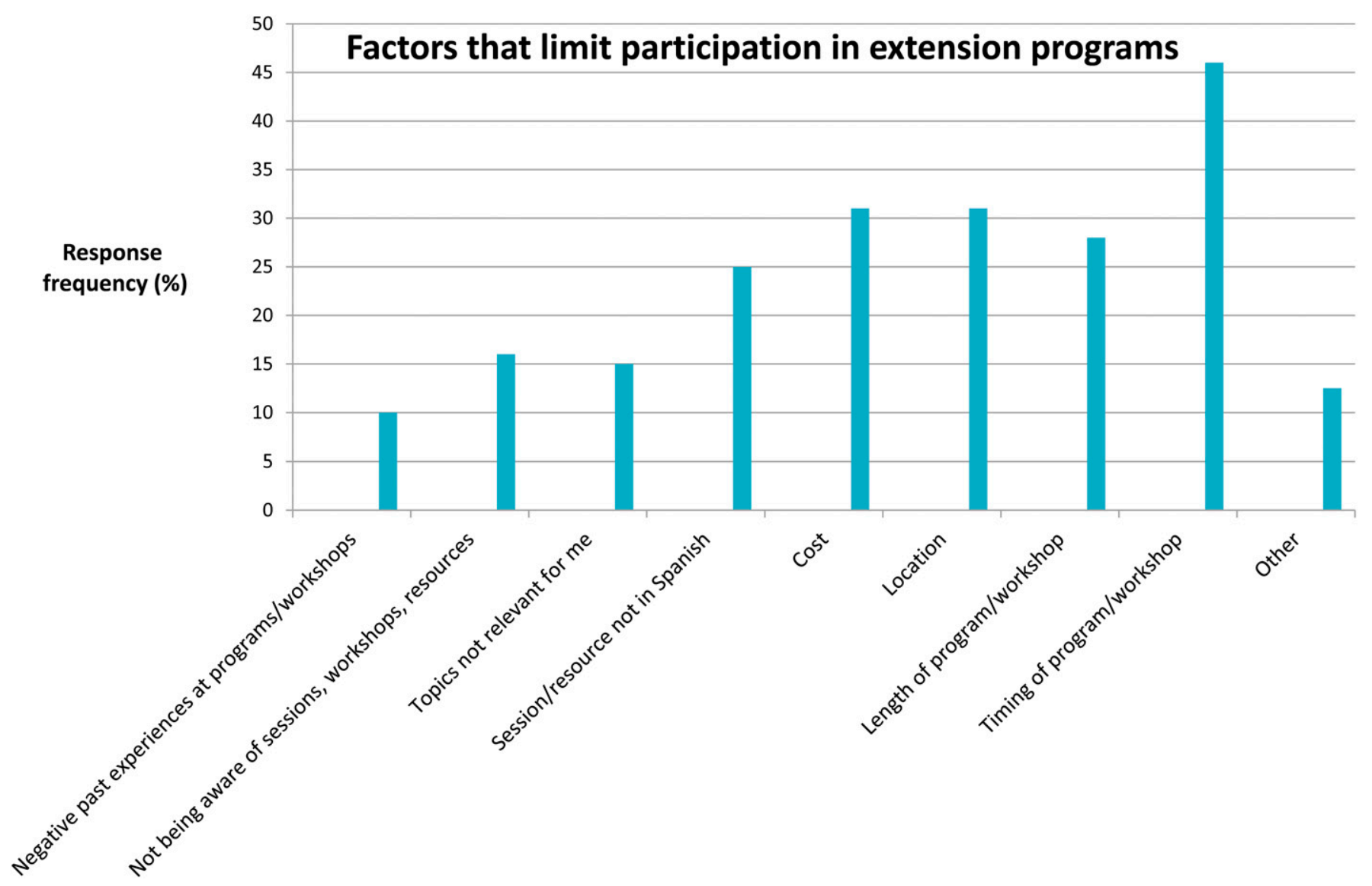

Fig. 3. Factors that have limited, or would limit, survey participants $(n=61)$ from participating in extension educational activities and/or using extension resources for Hispanic/Latino specialty crop growers. Growers who completed a postprogram, written questionnaire following three interactive workshops conducted in Spanish had the opportunity to select multiple limitations regarding extension program participation. 
interactive workshops included questions designed to measure knowledge gained and practices changed, and although not a central objective of the project reported here, $66 \%$ reported an increase in knowledge in at least two subject areas, $62 \%$ planned to improve a horticultural skill, and 50\% planned to adopt a new practice to protect the environment. As reported in other studies on outreach to Hispanic/ Latino audiences (Olsen et al., 2009; Vega et al., 2016), consistent presence and programming will be important to the long-term, measureable success of this initiative.

\section{Implications for university extension and outreach}

In regions of the country where Hispanic/Latino growers have been involved in specialty crop production for more than two generations, many are now farm owners and industry leaders, as indicated in the most recent Census of Agriculture (USDA, 2014). University extension educators and specialists have an opportunity to provide significant support for this promising next generation of specialty crop producers through relevant, interactive outreach and educational programming. Based on the preliminary needs assessments described in this paper, future extension efforts will include 1) learner engagement by use of social media in Spanish, 2) holding some educational programs specifically for Hispanic/ Latino producers, 3) holding educational programs at the farms of Hispanic/Latino growers, and 4) a variety of bilingual, educational formats including on-farm demonstrations and study circles, tours of other growers' farms, self-paced online courses and videos, and hands-on workshops. As with any community of growers or learners, Hispanic/Latino stakeholders are diverse, and needs assessments will be ongoing.

\section{Literature cited}

Barbercheck, M., K.J. Brasier, N.E. Kiernan, C. Sachs, A. Trauger, J. Findeis, A. Stone, and L.S. Moist. 2009. Meeting the extension needs of women farmers: A perspective from Pennsylvania. J. Ext. 47 (3). 2 Dec. 2016. <https://www.joe. org/joe/2009june/a8.php>.

Dollisso, A.D. and R.A. Martin. 1999. Perceptions regarding adult learners' motivation to participate in educational programs. J. Agr. Educ. 40(4):38-46.

Farner, S., M.E. Rhoads, G. Cutz, and B. Farner. 2005. Assessing the educational needs and interests of the Hispanic population: The role of extension. J. Ext. 43 (4). 29 Aug. 2016. <http://www.joe. org/joe/2005august/rb2.php>.

Hobbs, B. 2004. Latino outreach programs: Why they need to be different. J. Ext. 42(4). 2 Dec. 2016. <https://www. joe.org/joe/2004august/comml.php>.

Irani, T., N.T. Place, and C. Mott. 2003. Integrating adult learning into extension: Identifying importance and possession of adult education competencies among county extension faculty. J. Southern Agr. Educ. Res. 53(1):164-177.

Johnson, S.B., H.S. Carter, and E.K. Kaufman. 2008. Learning styles of farmers and others involved with the Maine potato industry. J. Ext. 46(4). 24 Aug. 2016. <http://www.joe.org/joe/ 2010 june/rb2.php>.

Knowles, M.S., R.A. Swanson, and E.F. Holton, III. 2005. The adult learner: The definitive classic in adult education and human resource development. 6th ed. Elsevier, San Diego, CA.

Mullinix, K., L. Garcia, A. Lewis-Lorentz, and J. Qazi. 2006. Latino views of agriculture, careers and education: Dispelling the myths. North Amer. Colleges Teachers Agr. J. 47(4):2-11.
Olsen, C.S. and L. Skogrand. 2009. Cultural implications and guidelines for extension and family life programming with Latino/Hispanic audiences. Forum Family Consumer Issues 14(1). 9 Aug. 2016. <https://ncsu.edu/ffci/publications/ 2009/v14-nl-2009-spring/olsenskogrand.php>.

Ota, C., C.F. DiCarlo, D.C. Burts, R. Laird, and C. Gioe. 2006. Training and the needs of adult learners. J. Ext. 44(6). 2 Dec. 2016. <https://www.joe.org/joe/ 2010june/rb2.php>.

Penn State Extension. 2016. Start farming. 17 Nov. 2016. <http://extension. psu.edu/business/start-farming $>$.

Strong, R., A. Harder, and H. Carter. 2010. Agricultural extension agents' perceptions of effective teaching strategies for adult learners in the master beef producer program. J. Ext. 48(3). 2 Dec. 2016. <https://www.joe.org/joe/ 2010 june/ $>$.

Trede, L.D. and B.S. Whitaker. 2000. Educational needs and perceptions of Iowa beginning farmers toward their education. J. Agr. Educ. 4l(1):39-48.

U.S. Department of Agriculture (USDA). 2014. Ag census highlights: Hispanic farmers. 6 Apr. 2016. <http://www. agcensus.usda.gov/Publications/2012/ Online_Resources/Highlights / Hispanic_Farmers/Highlights_ Hispanic_Farmers.pdf $>$.

U.S. Department of Agriculture (USDA). 2016. Ag census highlights: U.S. horticulture in 2014. 6 Apr. 2016. <http:// www.agcensus.usda.gov/Publications/ 2012/Online_Resources/Highlights/ Horticulture/Census_of_Horticulture_ Highlights.pdf $>$.

Vega, L., B. Brody, and M. Cummins. 2016. Best practices for outreach and engagement to Latino audiences using community-based programs. J. Hum. Sci. Ext. 4(2):148-166. 